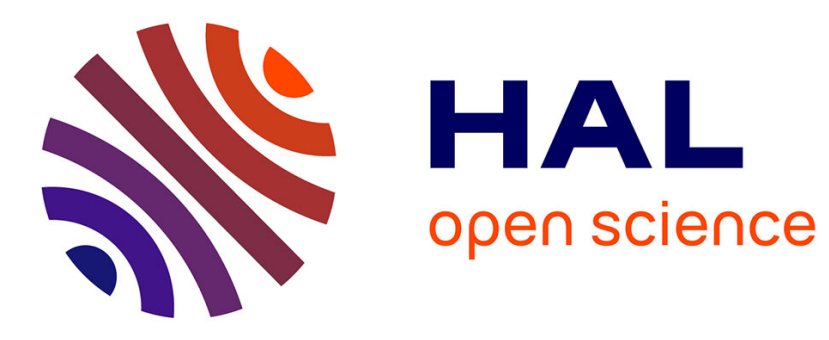

\title{
Computational evaluation of dynamic coefficients of thrust bearings; effect of artificial texturing on thermohydrodynamic performance
}

Georgios Koutsoumpas, Anastassios Charitopoulos, Christos Papadopoulos, Michel Fillon

\section{To cite this version:}

Georgios Koutsoumpas, Anastassios Charitopoulos, Christos Papadopoulos, Michel Fillon. Computational evaluation of dynamic coefficients of thrust bearings; effect of artificial texturing on thermohydrodynamic performance. Surface Topography: Metrology and Properties, 2020, 8 (2), pp.024009. 10.1088/2051-672X/ab8ffb . hal-03085055

\section{HAL Id: hal-03085055 https://hal.science/hal-03085055}

Submitted on 24 Dec 2020

HAL is a multi-disciplinary open access archive for the deposit and dissemination of scientific research documents, whether they are published or not. The documents may come from teaching and research institutions in France or abroad, or from public or private research centers.
L'archive ouverte pluridisciplinaire HAL, est destinée au dépôt et à la diffusion de documents scientifiques de niveau recherche, publiés ou non, émanant des établissements d'enseignement et de recherche français ou étrangers, des laboratoires publics ou privés. 


\title{
Computational Evaluation of Dynamic Coefficients of Thrust Bearings; Effect of Artificial Texturing on Thermohydrodynamic Performance
}

Georgios Koutsoumpas ${ }^{\mathrm{a}}$, Anastassios Charitopoulos ${ }^{\mathrm{a}, \mathrm{b}}$, Christos I. Papadopoulos ${ }^{\mathrm{a}}$, Michel Fillon ${ }^{\mathrm{b}}$

a School of Naval Architecture and Marine Engineering, National Technical University of Athens, 9 Iroon Polytechniou Str., Zografou 15780, Greece.

b Institut Pprime, CNRS - University of Poitiers - ISAE- ENSMA, Dpt GMSC, Futuroscope Chasseneuil, France.

\begin{abstract}
:
Fluid film thrust bearings are commonly used in industry, providing durable and reliable operation at high values of load carrying capacity, accompanied by low friction losses. A major advantage of hydrodynamic fluid film bearings, over other types of bearings, is their enhanced dynamic behaviour, especially under transient or impact loads. Currently, a systematic approach to identify the dynamic coefficients of thrust bearing geometrical configurations utilising high complexity CFD simulation data has not yet been established. It is therefore imperative to develop a method, capable of evaluating the dynamic characteristics of complex bearing designs and allow the evaluation of bearing response under transient loads. In the present work, a computational approach is proposed to estimate the stiffness and damping coefficients of fluid-film thrust bearings. A CFD-based ThermoHydroDynamic (THD) numerical model of the bearing is developed and utilised for performing an initial steady-state simulation at given rotational speed and thrust load, as well as subsequent transient simulations at increasing or decreasing thrust loads. The former simulation is used to calculate the stiffness coefficient of the bearing at the specified conditions, while the latter are appropriately post-processed to estimate the damping coefficient of the bearing at different values of rotor acceleration. The procedure is repeated at different operating conditions, yielding a map of the dynamic coefficients of the bearing. Finally, a single degree of freedom model is generated, which utilises the calculated values of dynamic coefficients to evaluate transient bearing performance under any given thrust load history. The proposed methodology is applied to compare the dynamic response characteristics of a conventional sector-pad tapered-land thrust bearing and a textured tapered-land thrust bearing of the same principal dimensions.
\end{abstract}

Keywords: THD; Thrust bearing; Stiffness coefficient; Damping Coefficient; Artificial Surface Texturing; CFD. 


\section{Introduction}

Today, thrust bearing applications demand high efficiency designs, in order to minimise friction losses. To that end, bearings of smaller principal dimensions are selected, resulting in more heavily loaded designs, which operate at lower values of minimum film thickness. Thus, the dynamic behaviour of such bearings, becomes a significant factor of the design process, in order to avoid contact, due to impact loads. The transient response of thrust bearings under impact loads depend on the stiffness and damping coefficients, which are a function of bearing operating parameters (rotational speed, thrust load, oil temperature). In order to evaluate those coefficients, a systematic method needs to be established.

Recently, due to the increased computing power available, computational methods have proven to be a valid alternative to experimental methods which are expensive and difficult to set-up. Due to the complex computations involved in the physics of the problem, the available literature is quite recent. The two main approaches to computational methods involve either the use of the Reynolds' equations or the full Navier-Stokes (N-S) equations. The Reynolds' equations are derived from the N-S equations by introducing certain assumptions to simplify the physics of the problem. Therefore, they are simpler to solve, but their results are less accurate.

A study conducted by Storteig and White [1] on tapered-land thrust bearings solved the Reynolds' equation using a 1-D finite element technique considering the hot oil carry-over effect to calculate its dynamic coefficients. The results showed a relatively good agreement with coefficients calculated with 2-D methods.

Zhu and Zhang [2] examined the transient axial response of a sector-shaped thrust bearing using a finite difference method to solve the Reynolds' equation. The results highlighted the significance of a nonlinear analysis and that the dynamic coefficients depend strongly on the initial film thickness. Nica [3] in his work managed to couple the Reynolds equation with the energy equation, and heat conduction equations. He concluded that the effect of the temperature distribution is crucial on the evaluation of bearing performance. In reference [4], Jang and Lee presented the two methods that are commonly used to calculate stiffness and damping coefficients. The first, considered as the physical perturbation method, consists in differentiating the forces with respect to finite displacements (for stiffness) and finite velocities (for damping). Regardless of the simplicity of the method, it requires a significant amount of computing time, and the accuracy depends on the perturbation amplitude. The latter is the mathematical perturbation method and uses the finite element method on the perturbed Reynold's equation. In [5], Srikanth et al. used a finite difference method to solve the Reynolds' equation and calculate the pressure in the oil film of tilting pad thrust bearings. Variations of the film thickness and runner axial velocity allow the calculation of stiffness and damping coefficients.

Papadopoulos et al. [6] proposed a computational method to determine the stiffness and damping coefficients of thrust bearings using Computational Fluid Dynamics (CFD). The method acknowledged both translational and tilting motion of the bearing. A hydrodynamic model was set in a steady-state condition (constant rotational speed and minimum film 
thickness values). Subsequently, a translational or tilting micro-perturbation was forced, altering the axial and tilting velocities. The damping coefficient was calculated by the ratio of the difference of load capacity (for the translational motion) or the average moment (for the tilting motion) to the velocity alteration. Finally, the model was allowed into a new steadystate which allowed the calculation of the stiffness coefficient using the minimum film thickness variations instead of the velocity. The proposed method was applied for smooth and textured pad bearing with results that confirmed published data. In [7], the dynamic coefficients of foil thrust bearings were calculated with CFD tools by imposing a sinusoidal motion to the rotor. Snyder and Braun [8] studied the difference between transient Reynolds' and N-S equations through a simple slider under harmonic loading. Similar procedures were implemented in [9-10], regarding the dynamic coefficient of journal bearings. A similar approach to that proposed by Papadopoulos et al. [6] was used in [11] by Vieira and Cavalca, who solved the Reynolds' equation, instead of the N-S equations, to determine the dynamic coefficients for both axial and tilting motions of a tapered-land thrust bearing.

In the present work, a novel procedure is proposed to calculate the transient response of fluid film thrust bearings using a CFD-based approach. In particular, a Thermohydrodynamic (THD) CFD method is employed to calculate the dynamic coefficients of a tapered-land and a surface textured bearing of the same principal dimensions, operating at the same conditions. Their performance under transient loads is calculated using a single degree of freedom lumped-mass model, which takes into consideration the dynamic coefficients calculated by the CFD-based THD simulations. A CFD-based THD approach was preferred over the simplified Reynolds' equation approach, since the latter does not account for pressure and temperature variations in the cross-flow (film thickness) direction, neglects fluid inertia forces and cannot model the hot-oil carry-over phenomenon between consecutive bearing pads. A THD approach is necessary in order to include heat effects, which are not negligible due to temperature differences and viscous dissipation effects, by additionally solving the energy equation, allowing the local calculation of viscosity to achieve higher precision.

\section{Problem setup}

\subsection{Calculation of stiffness and damping coefficients}

In order to calculate the stiffness and damping coefficients of a fluid film thrust bearing, a Thermohydrodynamic (THD) CFD analysis has been conducted (see Section 2.3 for details). The analysis consists of a steady state simulation followed by a transient one. In the steady state, the bearing is set at a constant minimum film thickness $h$ and the load $F_{\text {static }}$ is determined. This permits the calculation of the stiffness coefficient (Hooke's law), eq. (1):

$$
k(h ; \omega)=\frac{F_{\text {static }}}{h}
$$

As a result, the stiffness coefficient is based on constant minimum film thickness and does not include any dynamic aspects, which are included in the damping coefficient. The 
procedure is repeated for various minimum film thickness values in order to generate a stiffness coefficient to minimum film thickness function.

Subsequently, for each minimum film thickness considered in the stiffness coefficient calculation, a perturbation of the minimum film thickness from the previous steady state condition (initial state) is examined using two transient models. In the first model, the rotor is accelerated axially with a constant acceleration, until a specific displacement $\Delta \mathrm{x}$ (namely 0.1 $\mu \mathrm{m}$ ) from the initial state is reached, to approach the pad, leading to an increase of the generated force. The second model considers the same acceleration profile forcing the rotor away from the pad, decreasing the generating force. Due to zero initial axial velocity, the axial motion can be described as follows:

$$
h=\left.h\right|_{t=0}+\frac{1}{2} \ddot{x} \cdot t^{2}
$$

The transient force values $F_{\text {trans, }}$, resulting from each transient simulation, are considered to be formed by a static part, which has been calculated by the steady-state simulation, and a dynamic part, as it appears in the following equation:

$$
F_{\text {trans }}(h+\Delta x, \dot{x}, \ddot{x} ; \omega)=F_{\text {static }}(h+\Delta x ; \omega)+F_{\text {dynamic }}(h+\Delta x, \dot{x}, \ddot{x} ; \omega)
$$

The dynamic part of the total force is used to calculate the dynamic coefficient as it appears in Eq. (4) and Eq. (5) leading to a damping coefficient for each transient simulation:

$$
\begin{gathered}
c_{\text {distancing }}(h, \dot{x}, \ddot{x} ; \omega)=\frac{F_{\text {dynamic,distancing }}}{\dot{x}}=\frac{F_{\text {dynamic,distancing }}}{\ddot{x} \cdot t} \\
c_{\text {approaching }}(h, \dot{x}, \ddot{x} ; \omega)=\frac{F_{\text {dynamic,approaching }}}{\dot{x}}=\frac{F_{\text {dynamic,approaching }}}{\ddot{x} \cdot t}
\end{gathered}
$$

As demonstrated from the results listed in Table 1, the resulting damping coefficients are independent of the perturbation displacement value. The damping coefficients for the taperedland bearing at a constant minimum film thickness and acceleration have been calculated for three different perturbations. The percentage difference from the $0.1 \mu \mathrm{m}$ case is calculated and is within the computational error margin.

Table 1: Perturbation analysis results.

\begin{tabular}{lcccc} 
Perturbation $\Delta \mathbf{x}[\boldsymbol{\mu m}]$ & \multicolumn{2}{c}{ Damping coefficient $[\mathbf{N} \cdot \mathbf{s} / \mathbf{m}]$} & \multicolumn{2}{c}{ Difference [\%] } \\
\hline & Distancing & Approaching & Distancing & Approaching \\
0.05 & 18,673 & 18,771 & 3.6 & 5.4 \\
0.1 & 19,370 & 19,849 & - & -
\end{tabular}




\subsection{Single Degree of Freedom (SDOF) model}

The transient thrust bearing response has been predicted through a single degree of freedom lumped-mass model, developed with MATLAB/Simulink. In this specific case, only axial motions have been considered. The previously derived bearing-specific coefficient maps generated through the afore mentioned methodology, and are inputted into the SDOF model to calculate the restoring and damping forces at each time-step. The bearing setup is always under a state of compression and the rest position distance $h_{\text {rest }}$ has been considered. Initially, the rotor is placed at the rest position, thus, there is no external or reaction force. Any load displaces the rotor from this position to a distance $x$, depending on the magnitude, compressing the rotor, as shown in Fig. 1. Therefore:

$$
h(t)=h_{\text {rest }}-x(t)
$$

Figure 1: Single degree of freedom model representation.

The model's motion is described by the following equation:

$$
m \cdot \ddot{x}+c \cdot \dot{x}+k \cdot h=F(t) \Rightarrow \ddot{x}(t)=\frac{1}{m}[F(t)-c \cdot \dot{x}-k \cdot h]
$$

In Eq. (7), $m$ expresses the rotor's mass, while $k$ and $c$ are the stiffness and damping coefficients, respectively, being calculated by the CFD-based THD computational approach. The SDOF equation has been used to calculate the rotor axial acceleration at each time-step. Zero initial conditions are set for the displacement and the velocity. Time integration calculates the velocity and the displacement at each time-step. Subsequently, stiffness and damping coefficients are extracted from the maps created, and the restoring and damping forces are defined. While the stiffness coefficient only requires the minimum film thickness 
to be defined, the damping coefficient is also a function of the velocity and acceleration as stated above. To deal with the issue, all the interpolations for the damping coefficient relationship with acceleration have been done considering that acceleration is equal to the RMS value of the load's acceleration $a_{\text {load }}(t)=\frac{F(t)}{m}$. Depending on the direction of motion, either the distancing or the approaching coefficient is used $(\dot{x}>0 \rightarrow$ approaching, $\dot{x}<0 \rightarrow$ distancing). The angular velocity $\omega$ has been considered to remain constant for each simulation. The above described methodology is represented graphically in Fig. 2. If a constant force is applied, the resulting minimum film thickness from the SDOF model, should be equal to that of the steady-state CFD model. Thus, the stiffness coefficient does not include any dynamic parts.

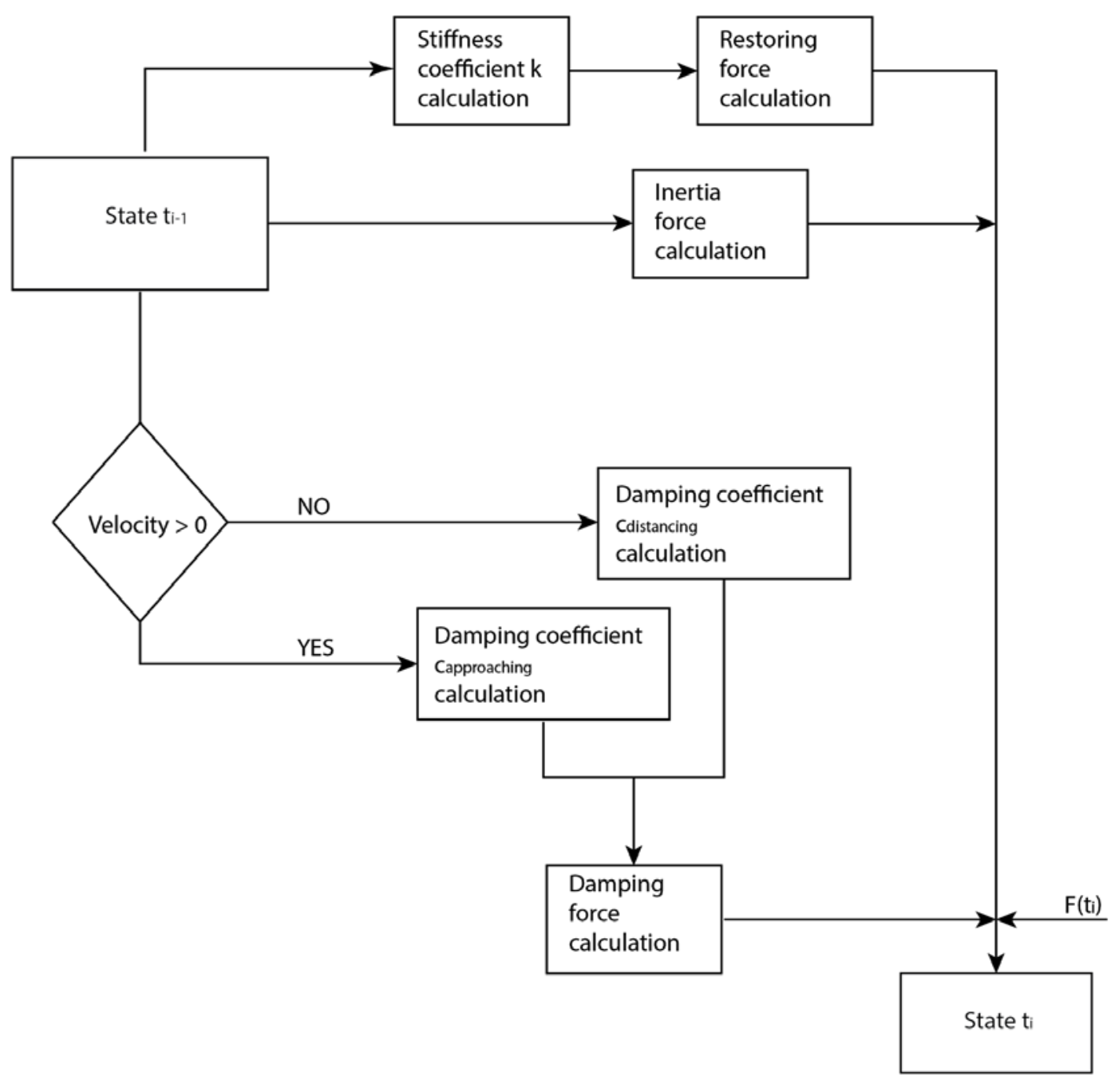

Figure 2: Bearing's response calculation procedure.

\section{Thermohydrodynamic (THD) Model setup}

The steady-state THD model has been based on that developed by Charitopoulos et al. in [1213 ] and solves the Navier-Stokes equations coupled with the Energy equation to account for thermal effects by simulating a conjugate heat transfer problem between lubricant, pad and 
rotor. Cavitation, viscous dissipation and the temperature dependency of the lubricant's viscosity have also been considered.

The equations, solved with the CFD code ANSYS CFX involving an incompressible flow, neglecting gravitational and external body forces, are:

Mass conservation equation:

$$
\nabla \cdot \vec{u}=0
$$

Momentum equations:

$$
\rho \frac{D \vec{u}}{D t}=-\nabla p+\mu \nabla^{2} \vec{u}
$$

Fluid domain energy equation:

$$
\rho \cdot c_{p f} \cdot \vec{u} \cdot \nabla T=\nabla \cdot\left(\lambda_{f} \cdot \nabla T\right)-\tau: \nabla \cdot \vec{u}
$$

Solid domain energy equation:

$$
\nabla\left(\lambda_{s} \cdot \nabla T\right)=0
$$

where, $\vec{u}$ is the fluid velocity vector ( $\mathrm{m} / \mathrm{s}), p$ is the fluid pressure (Pa), $T$ is the fluid/solid temperature (K), $\tau$ is the viscous stress tensor (Pa), $\rho$ is the oil density $\left(\mathrm{kg} / \mathrm{m}^{3}\right), \mu$ is the oil dynamic viscosity $(\mathrm{kg} /(\mathrm{m} \cdot \mathrm{s})), c_{p f}$ is the oil specific heat capacity $(\mathrm{J} /(\mathrm{kg} \cdot \mathrm{K})), \lambda_{f}$ is the oil thermal conductivity $(\mathrm{W} /(\mathrm{m} \cdot \mathrm{K}))$, and $\lambda_{s}$ corresponds to the thermal conductivity of the pad and the rotor $(\mathrm{W} /(\mathrm{m} \cdot \mathrm{K}))$.

\subsection{Bearing Geometrical Configurations}

The present study has considered two thrust bearing designs, both having an eight-sector pad configuration, whose main geometric characteristics are given in Table 2.

The first design is a tapered-land pad as shown in Fig. 3a. Each pad has a linear wedge where pressure buildup is developed and is followed by a land parallel to the rotor plane. Each pair of consecutive pads is separated by a groove. The bearing selected in this study has been derived from a parametric analysis (considering nominal minimum film thickness of $20 \mu \mathrm{m}$ ) to determine the optimal taper inclination and land extent, for the specific dimension, by maximising the load to friction torque ratio.

The second design is a parallel surface-textured bearing with the same principal dimensions (Fig. 3b). The density of the textured area has been set to $80 \%$, the configuration selected comprise of twenty-four (24) orthogonal dimples, four (4) in the radial direction and six (6) in the circumferential. The textured parameters, namely textured length, width, and depth have been selected by a genetic algorithm optimisation [14]. The selected parameter values are 
presented in Table 2 and are the resulting optimal geometry generated by Chalkiopoulos et al. [15].

Figure 3: Geometrical configurations: (a) Tapered land bearing, (b) Textured pad bearing.

Table 2: Thrust bearing geometrical characteristics.

\begin{tabular}{|c|c|c|c|c|}
\hline Parameter & Symbol & Unit & \multicolumn{2}{|c|}{ Value } \\
\hline Geometry & & & Tapered-land & Textured \\
\hline Optimum $\mathrm{H}_{\text {min }}$ & & {$[\mu \mathrm{m}]$} & 20 & 20 \\
\hline Number of pads & & & 8 & 8 \\
\hline Outer diameter & $\mathrm{D}_{\text {outer }}$ & {$[\mathrm{mm}]$} & 90 & 90 \\
\hline Inner diameter & $D_{\text {inner }}$ & {$[\mathrm{mm}]$} & 50 & 50 \\
\hline Rotor height & $\mathrm{H}_{\text {rotor }}$ & {$[\mathrm{mm}]$} & 10 & 10 \\
\hline Pad height & $\mathrm{H}_{\mathrm{pad}}$ & {$[\mathrm{mm}]$} & 6 & 6 \\
\hline Groove height & Hgroove & {$[\mathrm{mm}]$} & 4 & 4 \\
\hline Groove extent & $\varphi$ groove & {$\left[{ }^{\circ}\right]$} & 4.92 & 4.92 \\
\hline Taper extent & groove & {$\left[{ }^{\circ}\right]$} & 33.75 & - \\
\hline Taper inclination & $\mathrm{H}_{1}=\mathrm{H}_{\max }-\mathrm{H}_{\min }$ & {$[\mu \mathrm{m}]$} & 65 & - \\
\hline
\end{tabular}


Texturing length

Texturing width

Texturing dimple depth
$\%$

84.7

23

\subsection{Mesh Characteristics}

Regarding the tapered-land bearing, a structured mesh, whose fluid film and pad regions are depicted in Fig. 4a, totaling 730,000 elements has been generated, consisting of 121 elements across the circumferential direction, 65 across the radial direction and 90 elements across the height, 10 out of which inside the film.

As for the textured pad bearing, a mesh study has been conducted to select the mesh parameters. Regarding the pad domain, which appears together with the fluid domain in Fig. 4b, a dense hexahedral mesh has been utilised, composed of 910,000 elements. The fluid domain is discretised with hexahedral elements, utilising 15 layers of elements in the film thickness direction, while in the longitudinal and transverse directions, 150 and 60 elements have been used, respectively. The total number of elements in the fluid and rotor domains is 340,000 and 350,000, respectively.

During the transient simulation, as the rotor is forced to approach or move away from the pad, the fluid film gets thinner and thicker, respectively. As a result, as the element number in the fluid film thickness remains constant, the elements' dimension in the thickness direction is altered depending on the rotor's movement.

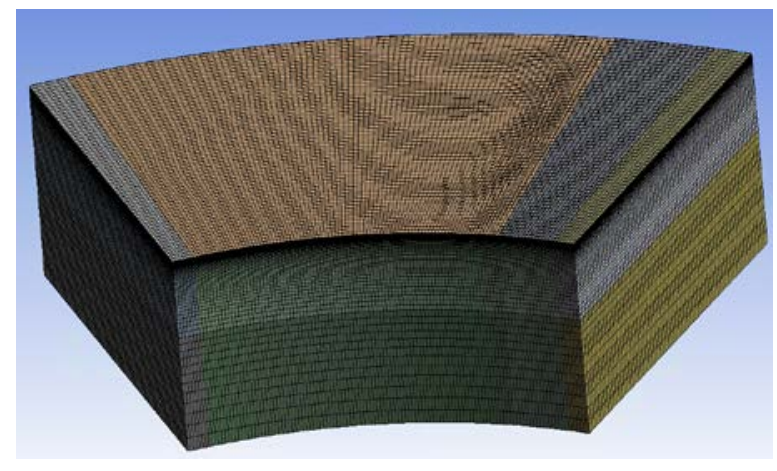

(a)

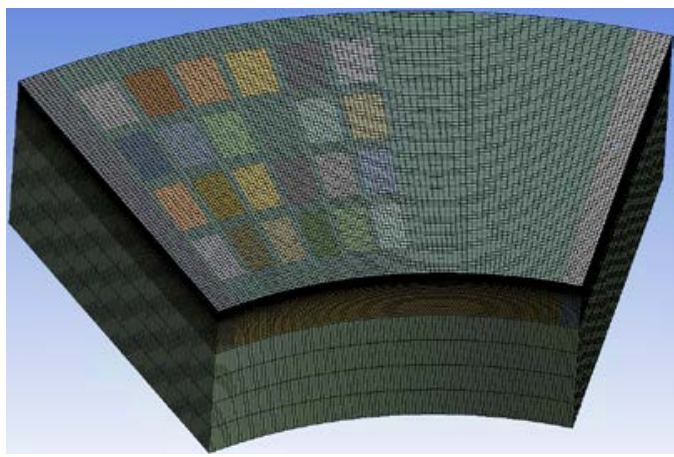

(b)

Figure 4: Mesh details: (a) tapered-land, (b) textured

\subsection{Boundary Conditions}

Both bearing designs have been modeled with the same boundary conditions. Regarding the fluid domain, the internal boundary (named inlet) has been considered a pressure inlet. The oil is fed at a constant pressure, however, depending on the pressure distribution in the fluid 
domain, oil may be pushed out in locations where the pressure is higher than the feeding value. On the other side, the fluid is allowed only to exit through the outlet. The outer side of the grooves is covered from the pad's body; thus, a wall is placed which does not allow oil outflow. Since only one pad has been considered, the sides have been modeled with a rotational periodicity interface to account for the adjacent pads. Finally, the two walls that are on the top and bottom side are the rotor and pad interfaces, respectively. In both cases, thermal effects have been taken into account by considering that the heat flux on either side of the interface is the same. In addition, while the pad is fixed in space, the rotor rotates, dragging the fluid's upper layer due to the no-slip condition. Consequently, the fluid has the same velocity field as the rotor. The hydrodynamic and thermal boundary conditions are listed in Table 3 and Table 4, respectively, while the boundaries can be seen in Fig. 5.

Table 3: Hydrodynamic boundary conditions details.

Fluid domains

Oil

Type:

Opening

Inlet

Pressure:

1 bar

Temperature:

$40^{\circ} \mathrm{C}$

Outlet

Type:

Outlet

Pressure:

0 bar

Wall

Type:

No-slip wall

boundary

Sides Rotational periodicity

Pad interface Heat flux and temperature continuity

Rotor interface

Angular velocity:

6,000 RPM

Heat flux and temperature continuity 
$\begin{array}{llc}\text { Solid domains } & \text { Rotor }\end{array}$

\begin{tabular}{|c|c|c|c|c|}
\hline \multirow[t]{2}{*}{ Inner } & \multicolumn{2}{|c|}{ Adiabatic boundary } & Heat transfer coefficient: & $\begin{array}{l}750 \\
\mathrm{~W} / \mathrm{mK}\end{array}$ \\
\hline & & & Ambient temperature: & $40^{\circ} \mathrm{C}$ \\
\hline \multirow{2}{*}{ Outer } & $\begin{array}{l}\text { Heat transfer } \\
\text { coefficient: }\end{array}$ & $25 \mathrm{~W} / \mathrm{mK}$ & Heat transfer coefficient: & $25 \mathrm{~W} / \mathrm{mK}$ \\
\hline & $\begin{array}{l}\text { Ambient } \\
\text { temperature: }\end{array}$ & $25^{\circ} \mathrm{C}$ & Ambient temperature: & $25^{\circ} \mathrm{C}$ \\
\hline \multirow{2}{*}{ Top / Bottom } & $\begin{array}{l}\text { Heat transfer } \\
\text { coefficient: }\end{array}$ & $25 \mathrm{~W} / \mathrm{mK}$ & Heat transfer coefficient: & $\begin{array}{l}1,000 \\
\mathrm{~W} / \mathrm{mK}\end{array}$ \\
\hline & $\begin{array}{l}\text { Ambient } \\
\text { temperature: }\end{array}$ & $25^{\circ} \mathrm{C}$ & Ambient temperature: & $40^{\circ} \mathrm{C}$ \\
\hline Sides & \multicolumn{2}{|c|}{ Rotational periodicity } & \multicolumn{2}{|l|}{ Rotational periodicity } \\
\hline Oil interface & \multicolumn{2}{|c|}{$\begin{array}{l}\text { Heat flux and temperature } \\
\text { continuity }\end{array}$} & \multicolumn{2}{|c|}{ Heat flux and temperature continuity } \\
\hline
\end{tabular}




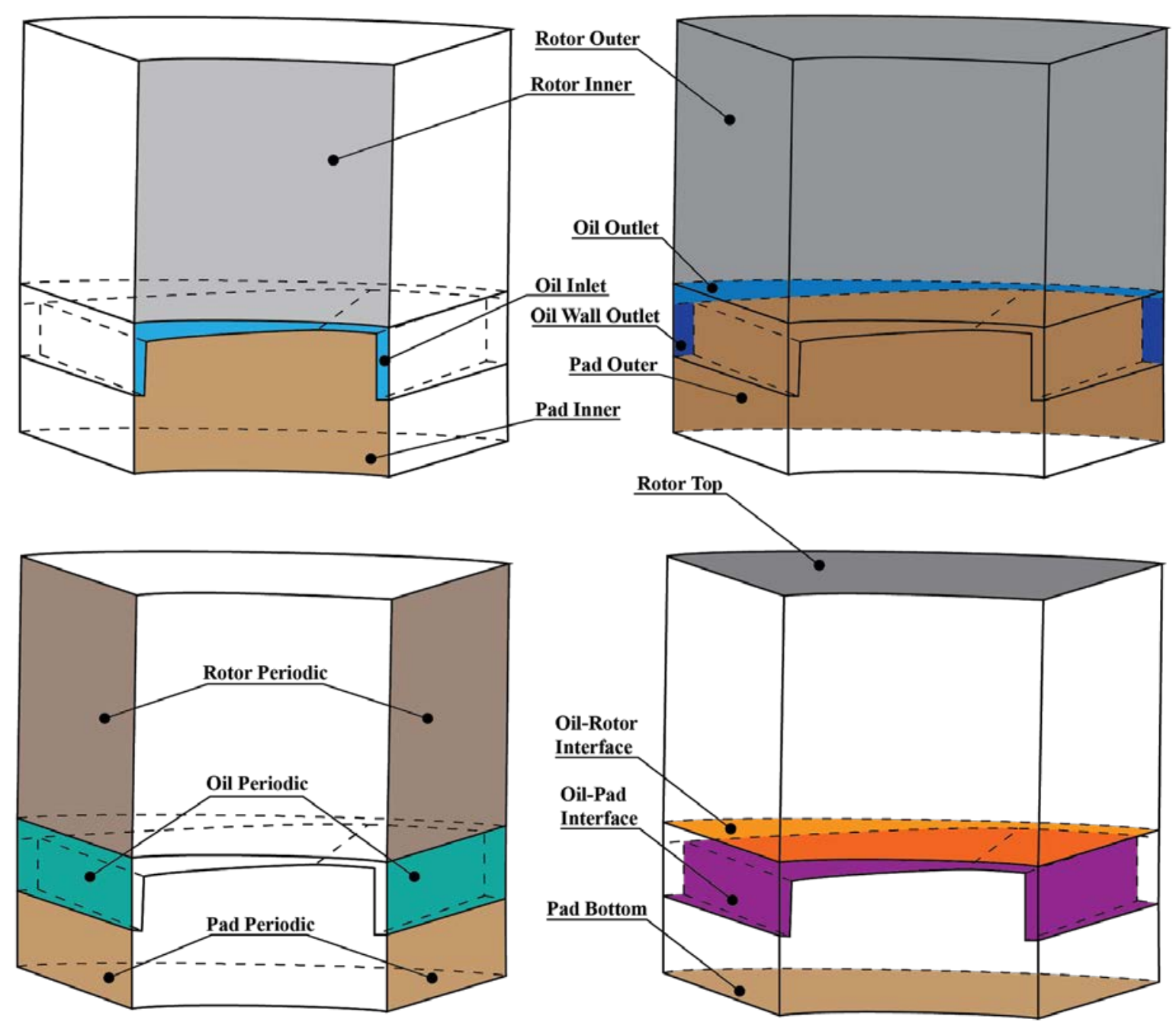

Figure 5: Boundary condition faces.

\subsection{Material thermophysical properties}

The lubricant considered in the present study is an ISO-VG 46 oil, whose thermophysical values are listed in Table 5. All properties, apart from viscosity, have been considered temperature independent. The viscosity temperature dependence has been approximated using the ASTM chart equation, an empirical equation based on McCoull and Walther's equation:

$$
((v+b))=a-c(T)
$$

where, $v$ is the kinematic viscosity (cSt), $T$ is the temperature $(\mathrm{K}), \mathrm{a}=9.02865, \mathrm{~b}=0.6$ and $\mathrm{c}=3.52681$.

Cavitation has been taken into consideration using the Rayleigh-Plesset model. Vapour pressure has been considered constant and equal to $50 \mathrm{kPa}$. Both rotor and stator have been considered to be made of steel, whose thermophysical properties are presented in Table 6. 


\begin{tabular}{lcccc}
\hline Description & Symbol & Unit & \multicolumn{2}{c}{ Value } \\
\hline Material & & & Vapour & Oil \\
Thermodynamic state & & & Gas & Liquid \\
Molar mass & $\mathrm{M}$ & $\mathrm{kg} / \mathrm{kmol}$ & 383.92 & 383.92 \\
Density & $\rho$ & $\mathrm{kg} / \mathrm{m}^{3}$ & 1.185 & 870 \\
Specific heat capacity & $\mathrm{C}$ & $\mathrm{J} / \mathrm{kgK}$ & 1004.4 & 2100 \\
Thermal conductivity & $\mathrm{k}$ & $\mathrm{W} / \mathrm{mK}$ & 0.0261 & 0.13 \\
Dynamic viscosity & $\mu$ & $\mathrm{N} \cdot \mathrm{s} / \mathrm{m}^{2}$ & $2.10 \mathrm{E}-05$ & - \\
Kinematic viscosity, $40^{\circ} \mathrm{C}$ & $v_{40}{ }^{\circ} \mathrm{C}$ & $\mathrm{cSt}$ & - & 47.26 \\
Kinematic viscosity, $100^{\circ} \mathrm{C}$ & $v_{100^{\circ} \mathrm{C}}$ & $\mathrm{cSt}$ & & - \\
\end{tabular}

Table 6: Thermophysical properties of the pad and rotor materials.

\begin{tabular}{lccc}
\hline Description & Symbol & Unit & Value \\
\hline Thermodynamic state & & Solid & \\
Molar mass & $\mathrm{M}$ & $\mathrm{kg} / \mathrm{kmol}$ & 55.85 \\
Density & $\rho$ & $\mathrm{kg} / \mathrm{m}^{3}$ & 7854 \\
Specific heat capacity & $\mathrm{Cp}$ & $\mathrm{J} / \mathrm{kgK}$ & 434 \\
Thermal conductivity & $\mathrm{k}$ & $\mathrm{W} / \mathrm{mK}$ & 60.5 \\
& & & \\
\hline
\end{tabular}

\subsection{Single degree of freedom parameters}

Regarding the single degree of freedom model, it has been considered that the rest position is at a distance of $h_{\text {rest }}=50 \mu \mathrm{m}$ from the pad and that the moving mass $m$ weighs $4 \mathrm{~kg}$. The model is set at an initial fixed value of $h$ for a total time ( $\left.t_{\text {steady }}\right)$ of $0.01 \mathrm{~s}$ followed by a transient loading condition (transient) that lasts $0.03 \mathrm{~s}$. Two initial conditions and four transient loads 
have been examined. Regarding the initial conditions, the first considers that the bearing is at the nominal operating condition minimum film thickness of $h_{\min }=20 \mu \mathrm{m}$, while the other considers that both designs are set at the same loading force $F=350.41 \mathrm{~N}$. As for the transient part, a step impact load (Fig. 6a), a simple sinus (Fig. 6b) and a sum of two sinusoidal functions (Fig. 6c) have been coupled with the first initial condition to evaluate the methodology proposed. Finally, a complex load (Fig. 6d), defined in Eq. (13) and Table 7, is coupled to both initial conditions to compare the dynamic performance of the two thrust bearing designs.

$$
\begin{aligned}
d F(t)= & A_{1} \cdot \sin \left(\frac{\omega}{2} t+\varphi_{1}\right)+A_{2} \cdot \sin \left(\omega t+\varphi_{2}\right)+A_{3} \cdot \sin \left(2 \omega t+\varphi_{3}\right)+A_{4} . \\
& \sin \left(4 \omega t+\varphi_{4}\right)+A_{5} \cdot \sin \left(8 \omega t+\varphi_{5}\right)+A_{6} \cdot \sin \left(16 \omega t+\varphi_{6}\right)
\end{aligned}
$$

Table 7: Load parameters.

\begin{tabular}{cccc}
\hline Amplitude & Value & Phase & Value \\
\hline $\mathrm{A}_{1}$ & 30 & $\varphi_{1}$ & 5.353297 \\
$\mathrm{~A}_{2}$ & 40 & $\varphi_{2}$ & 3.878171 \\
$\mathrm{~A}_{3}$ & 20 & $\varphi 3$ & 0.085219 \\
$\mathrm{~A}_{4}$ & 15 & $\varphi_{4}$ & 2.010225 \\
$\mathrm{~A}_{5}$ & 15 & $\varphi 5$ & 1.152626 \\
$\mathrm{~A}_{6}$ & 15 & $\varphi 6$ & 3.710464 \\
& & & \\
\hline
\end{tabular}

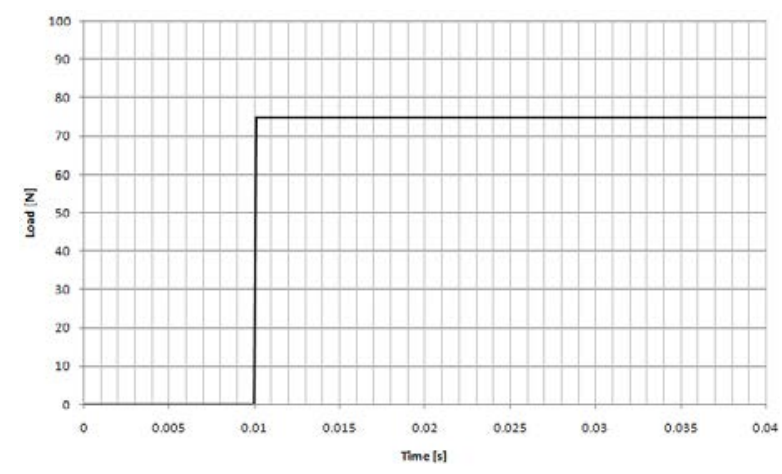

(a)

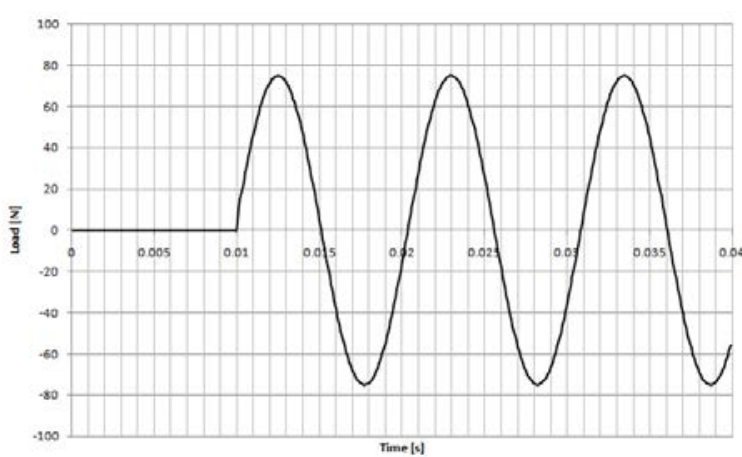

(b) 


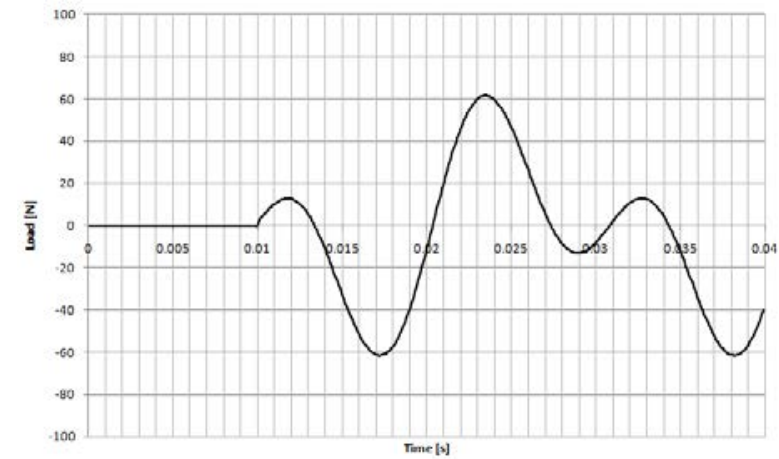

(c)

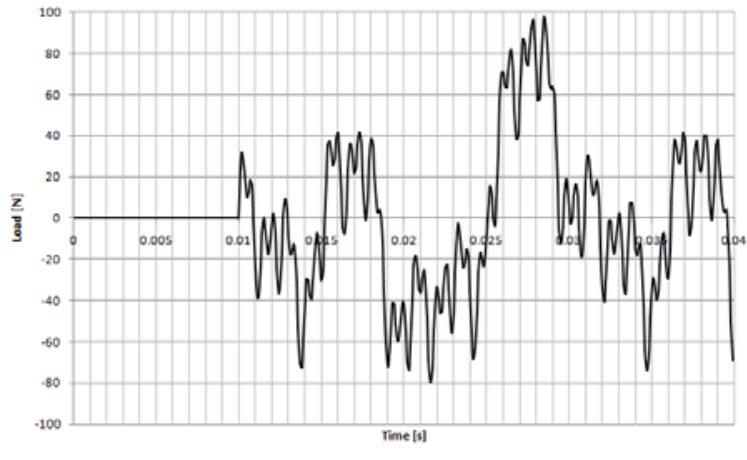

(d)

Figure 6: Transient load part scenarios: (a) Impact step, (b) Sinusoidal function, (c) Sum of two sinusoidal functions, (d) Complex load.

\section{Results}

In the following figures, the dynamic coefficients are displayed as a function of minimum film thickness $h_{\min }$, considering the nominal rotational velocity of $n=6,000 \mathrm{RPM}$. All the results that follow have been calculated for one pad. The tapered-land geometry generates higher load values for a specific minimum film thickness, in comparison to a textured geometry of similar principal dimensions at the same operating conditions. As a consequence, the stiffness coefficient, calculated by Eq. (1) is higher for the tapered-land geometry bearing, as shown in Fig. 7.

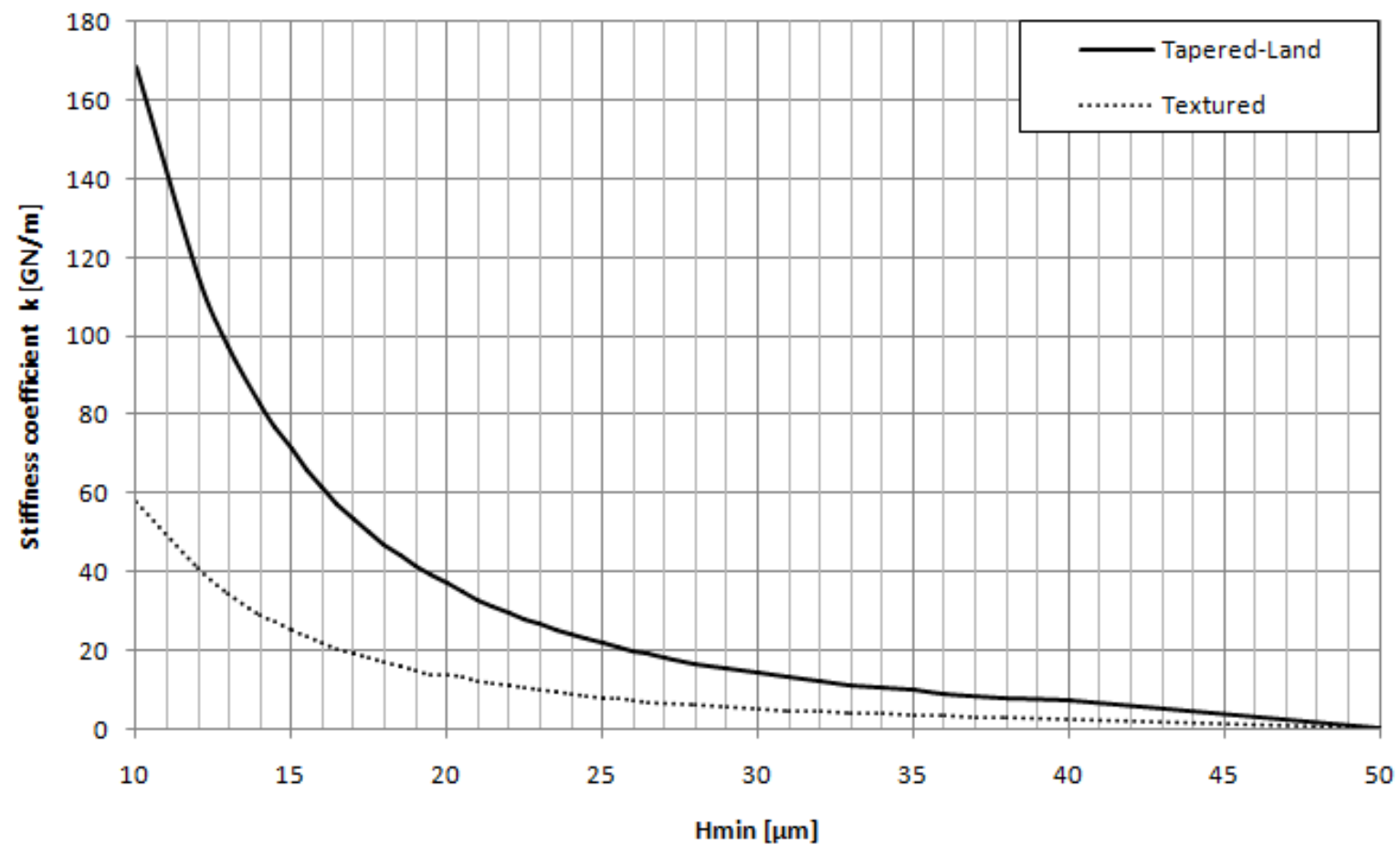

Figure 7: Stiffness coefficient $k$ to minimum film thickness $h_{\text {min, }}$,, $000 \mathrm{rpm}$. 
Regarding the damping coefficient, the textured bearing has a significantly higher damping effect and is less linear than the tapered-land's coefficient, both in the approaching and distancing directions, as it can be seen in Fig. 8 and 9, respectively.

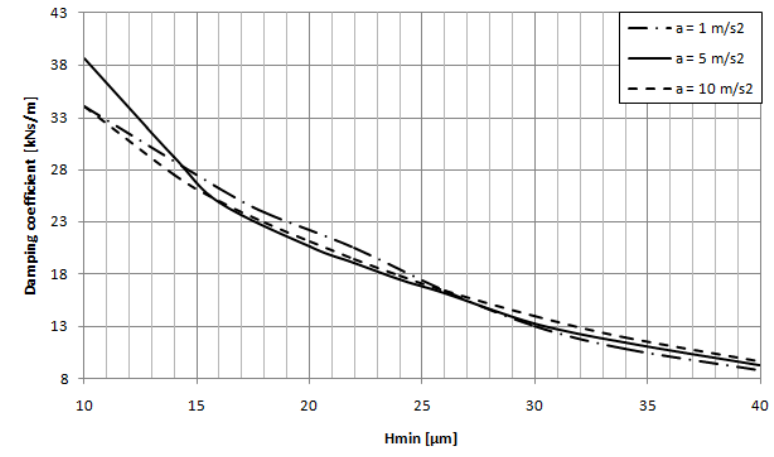

(a)

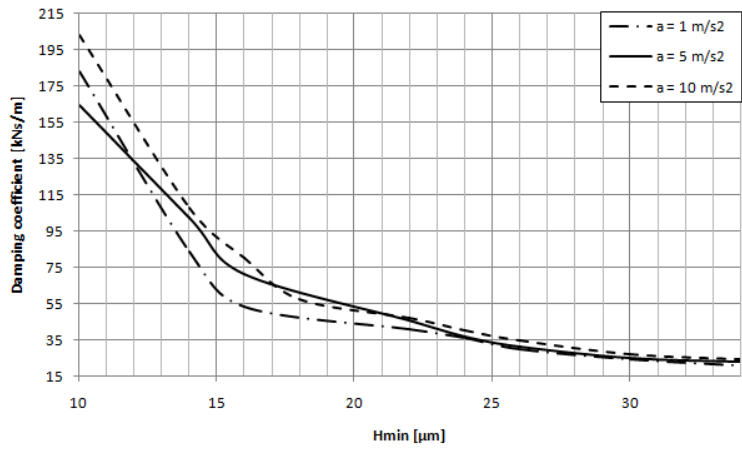

(b)

Figure 8: Distancing damping coefficient $c$ to minimum film thickness $h_{\min }, 6,000 \mathrm{rpm}$, (a) tapered-land bearing, (b) textured bearing.

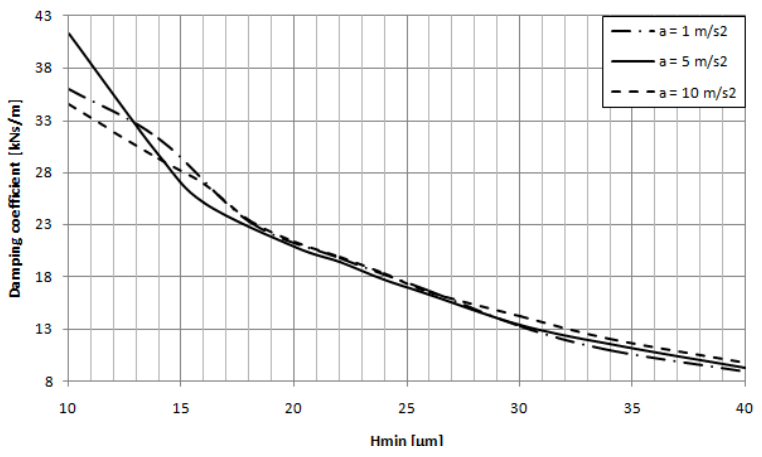

(a)

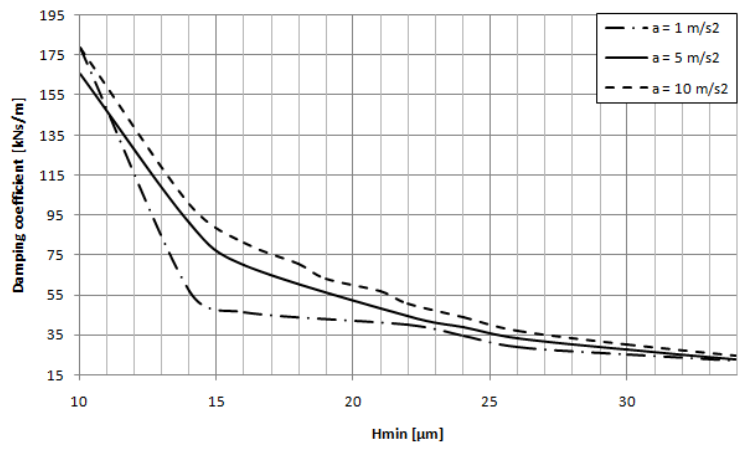

(b)

Figure 9: Approaching damping coefficient $c$ to minimum film thickness $h_{\min }, 6,000 \mathrm{rpm}$, (a) tapered-land bearing, (b) textured bearing.

The dynamic coefficients that resulted from the CFD analysis have been used in the single degree of freedom model for the two designs optimised at $h_{\min }=20 \mu \mathrm{m}$.

To evaluate the methodology, the transient loading scenarios displayed in Fig. 6a, 6b and 6c have been coupled to the initial condition of $20 \mu \mathrm{m}$ initial film thickness for the tapered-land design bearing and applied to the SDOF model. The resulting minimum film thickness time function has then been given as input to a transient CFD model of the bearing and the resulting force has been compared to the initial, as shown in Fig. 10.

As it can be seen from the comparison, while there are some differences, the initial load is predicted with good accuracy. In the step load scenario, there is only a $1 \%$ steady load difference between the applied load and the predicted through the method. In the simple sinus and sum of two sinus function scenarios, the major differences are noted at the peaks and valleys. In both cases, the maximum error is only a $2 \%$ of the initial load. Therefore, the methodology proposed can be trusted to give accurate results for the dynamic behaviour prediction. 


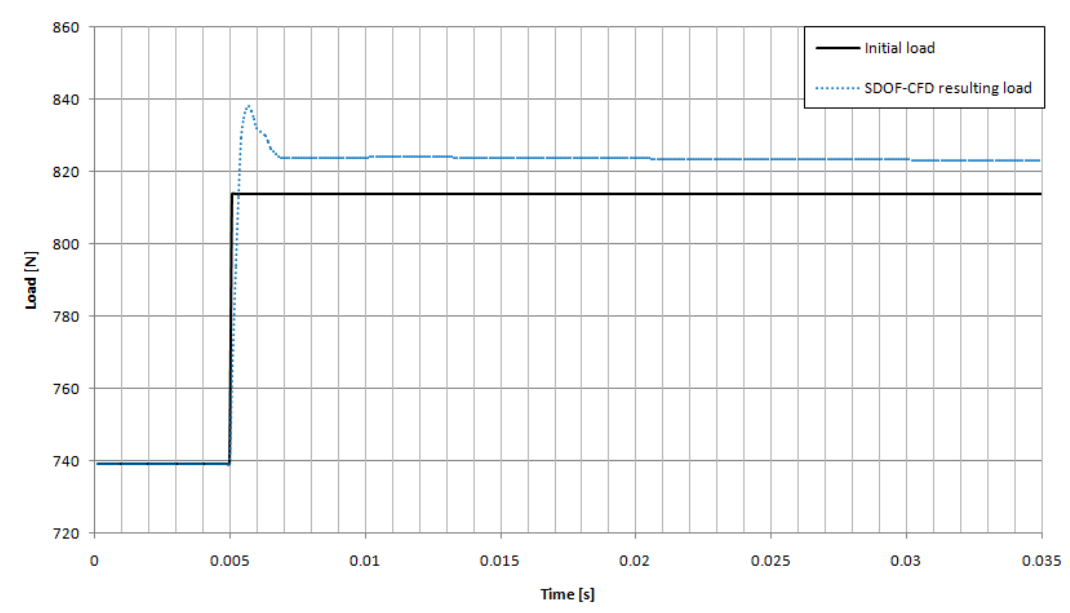

(a)

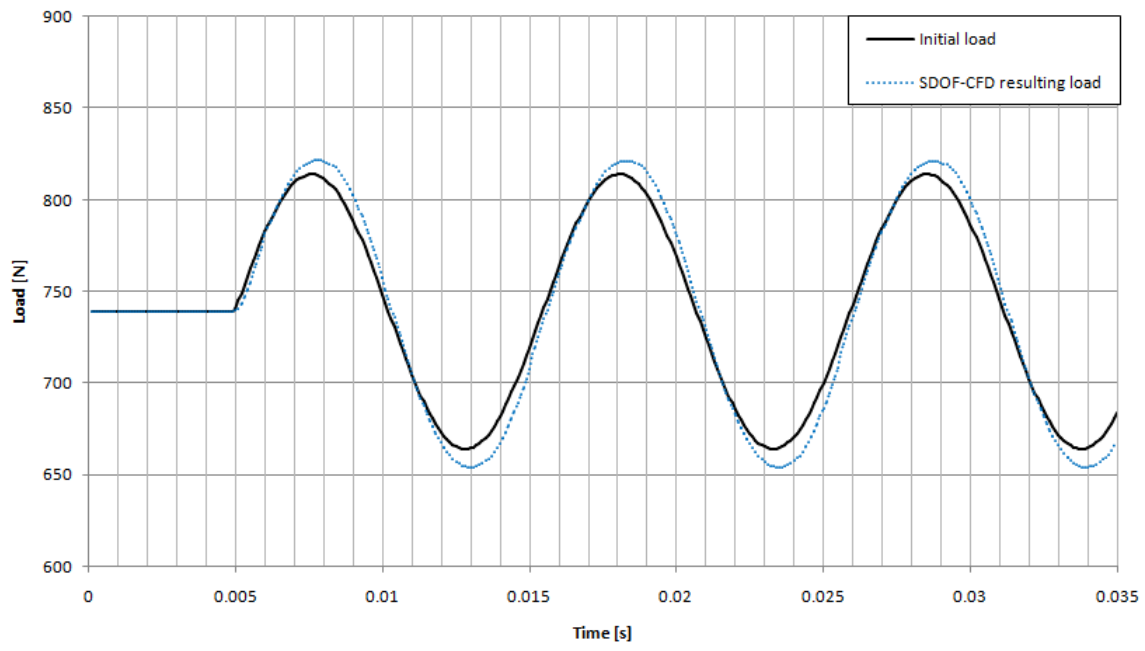

(b)

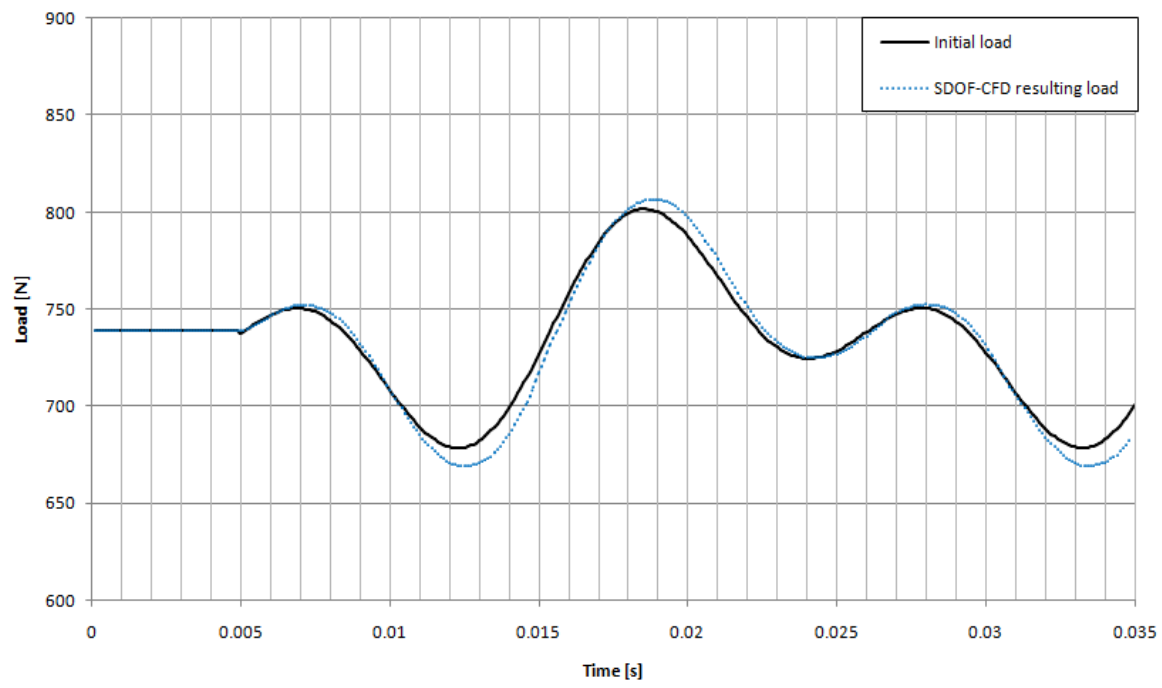

(c)

Figure 10: SDOF-CFD model evaluation. 
Subsequently, the complex transient load has been applied to the SDOF to predict the response of the two designs and examine their behaviour. The results are displayed in Figs. 11-14. The first two consider as initial condition that both designs are set at the same minimum film thickness while the remaining two consider the same initial force.

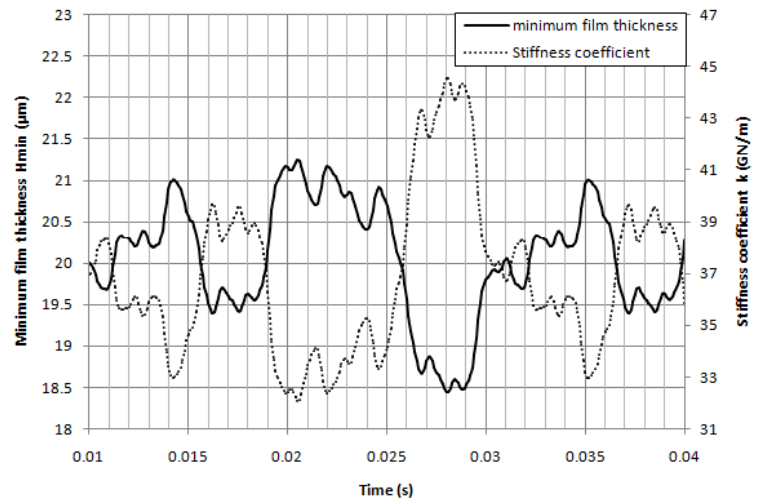

(a)

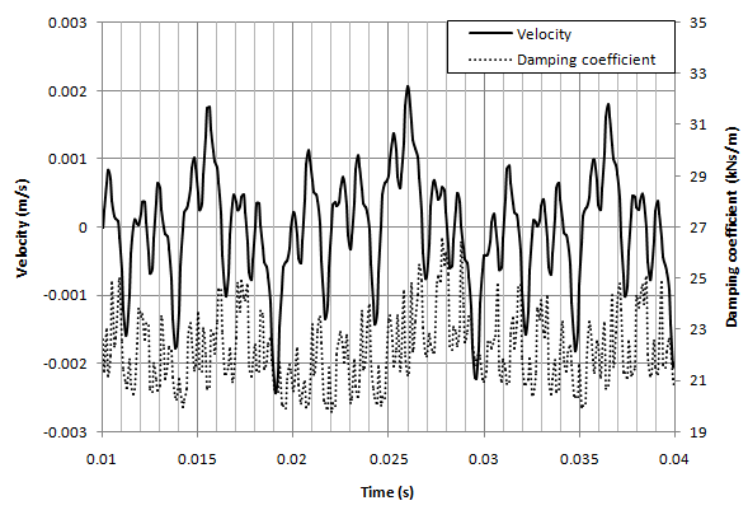

(b)

Figure 11: Tapered-land response - Initial condition $H_{\min }=20 \mu \mathrm{m}$, (a) Minimum film thickness and stiffness coefficient, (b) Velocity and damping coefficient.

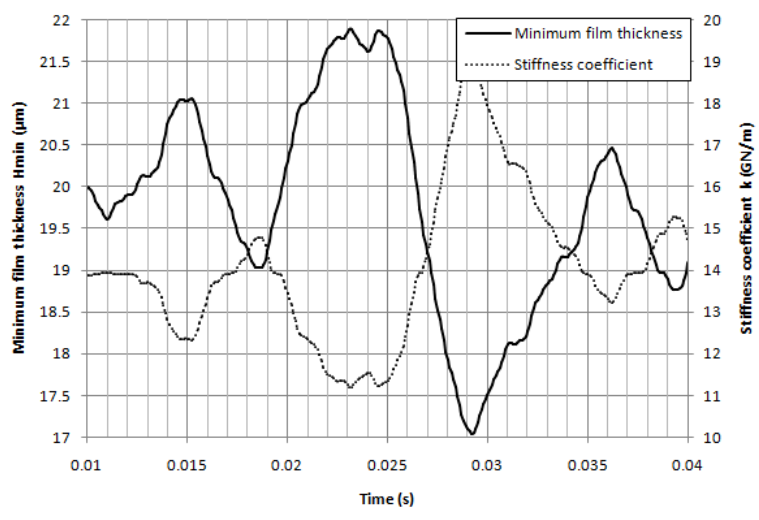

(a)

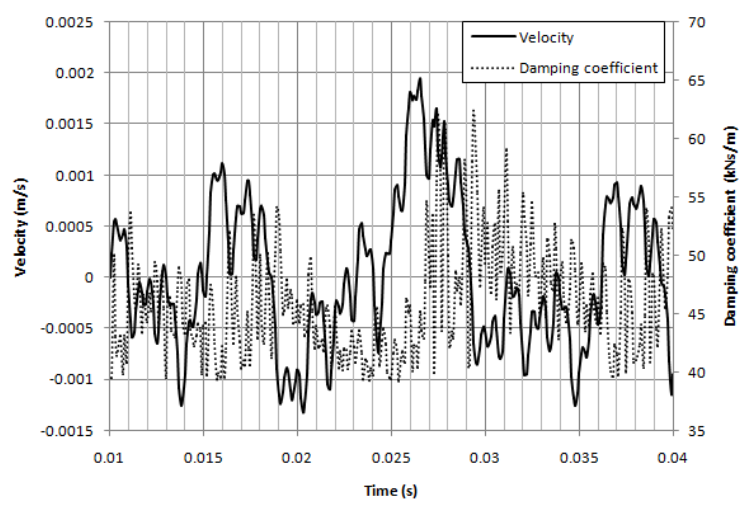

(b)

Figure 12: Textured response - Initial condition $H_{\min }=20 \mu \mathrm{m}$, (a) Minimum film thickness and stiffness coefficient, (b) Velocity and damping coefficient.

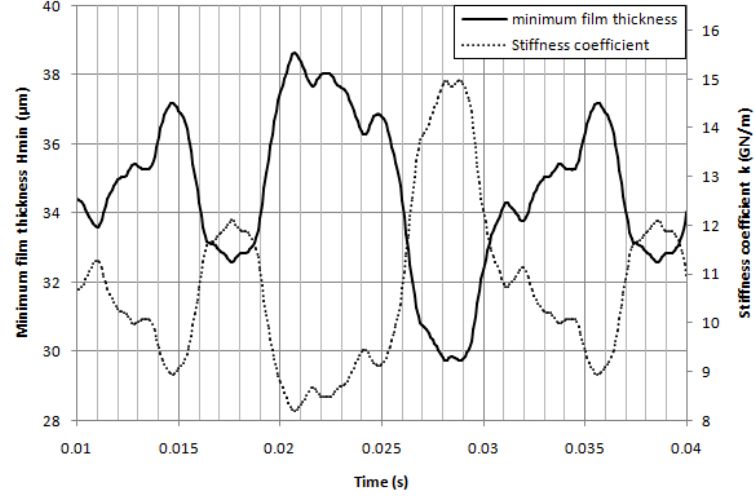

(a)

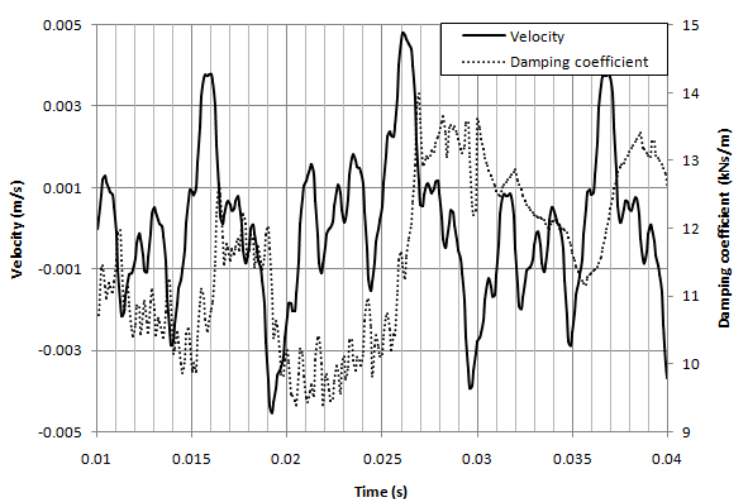

(b)

Figure 13: Tapered-land response - Initial condition $F=350.41 \mu \mathrm{m}$, (a) Minimum film thickness and stiffness coefficient, (b) Velocity and damping coefficient. 


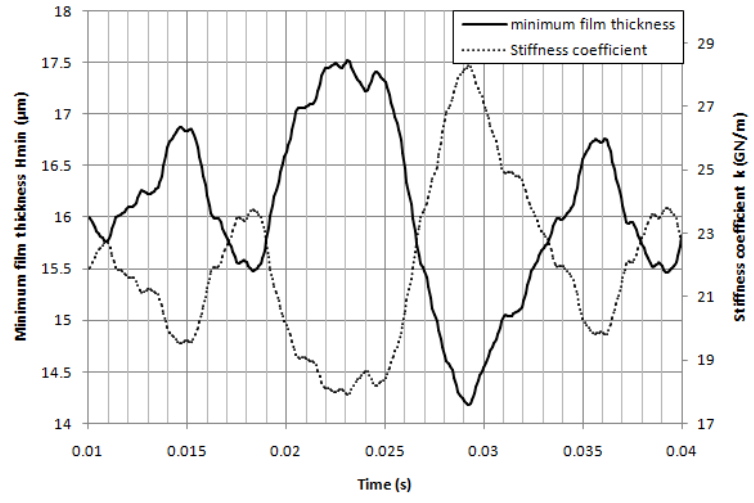

(a)

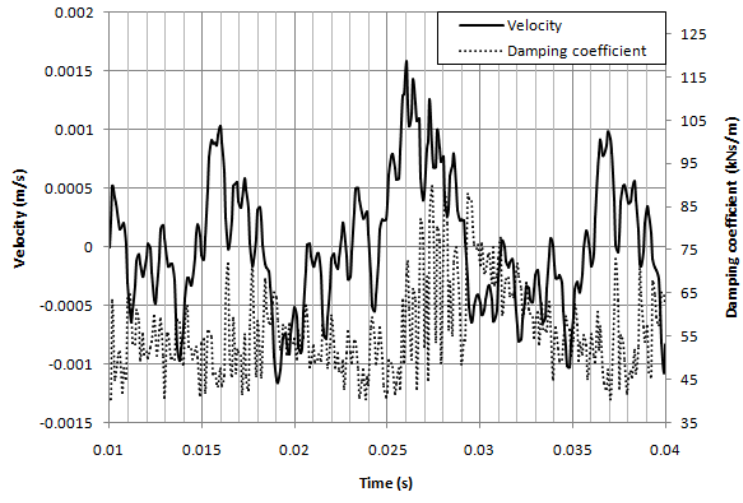

(b)

Figure 14: Textured response - Initial condition $F=350.41 N$, (a) Minimum film thickness and stiffness coefficient, (b) Velocity and damping coefficient.

As shown in Fig. 15, the textured design, due to the higher damping coefficient, is less affected by the rapid load changes in both scenarios. However, in the case of same initial minimum film thickness, the maximum displacement difference is higher since the stiffness coefficient is lower. On the other hand, when subjected to the same load, the tapered-land design operates at a higher minimum film thickness, resulting in a reduced stiffness coefficient. Consequently, the tapered-land's maximum displacement difference is higher in that case.

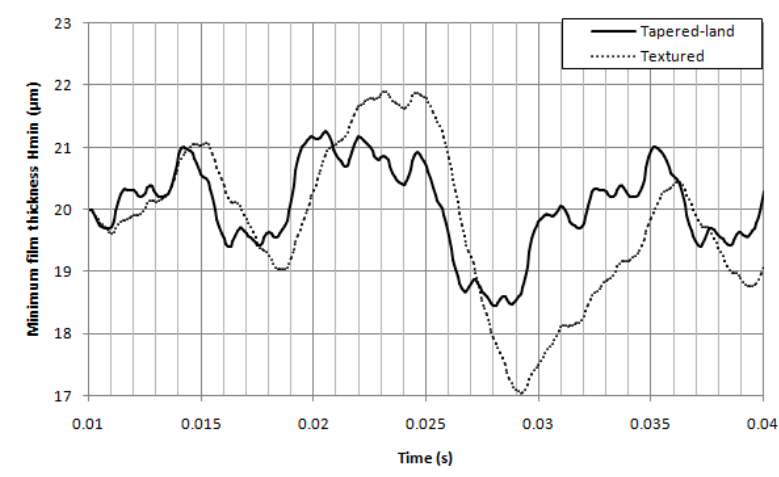

(a)

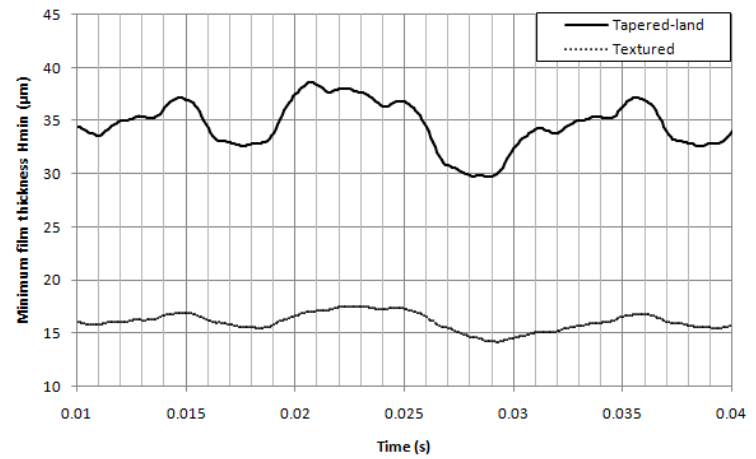

(b)

Figure 15: Tapered-land - Textured response comparison, (a) Initial condition $H_{\min }=20 \mu \mathrm{m}$, (b) Initial condition $\mathrm{F}=350.41 \mathrm{~N}$.

To evaluate the results of the single degree of freedom model, the displacement that resulted from the single degree of freedom model has been set as input to a transient simulation to compare the resulting load with the initial. The results, displayed in Fig. 16a and 16b, show the difference between the transient part of the imposed load and the calculated through the SDOF-CFD methodology load. 


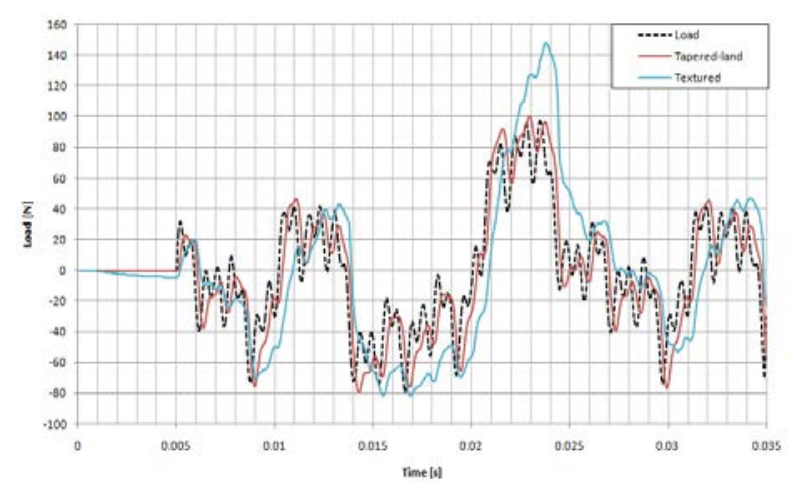

(a)

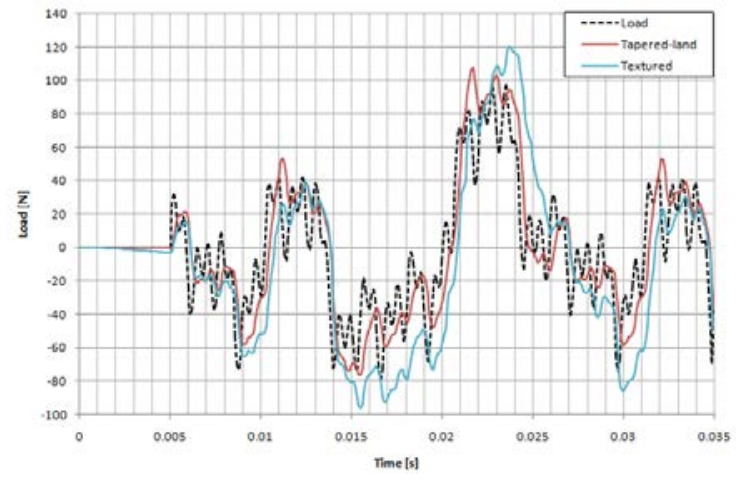

(b)

Figure 16: ANSYS-Simulink load comparison, (a) initial condition $H_{\min }=20 \mu \mathrm{m},(b) F=350.41 \mathrm{~N}$.

The results indicate that while both designs follow the load's trend, the tapered-land bearing's results are more accurate compared to the textured one. More specifically, in the first initial condition, the tapered-land's results are almost identical to the imposed load, while in the second initial condition there are some differences, which may be caused by the denser data set collected near the optimum minimum film thickness. Regarding the textured pad bearing, the results are not as accurate. However, the figures represent the results without the steady part of the load. For instance, the peak displayed in Fig. 16a between $0.02 s$ and $0.025 s$ is approximately only $6 \%$ higher compared to the total load.

\section{Conclusions}

In the present work, a procedure has been proposed to calculate the transient thrust bearing response using CFD analysis, comprising the following steps:

- Calculation of the dynamic coefficients of the bearing using a combination of steady-state and transient CFD-based THD simulations, at different values of minimum film thickness, as well as rotor direction and acceleration levels.

- Development of a SDOF dynamic model, capable of calculating the transient bearing response (rotor motion), for a given time-varying thrust load.

- Feeding of the rotor motion, predicted by the SDOF model, back to the CFD bearing model, and calculations of bearing performance using a time-dependent mesh deformation computational approach.

The proposed methodology has been applied to both a tapered-land and a parallel textured fluid film thrust bearings, permitting the prediction of bearing response under transient thrust loading. This includes a steady-state simulation, in which the rotor has been set at a specific minimum film thickness, and a perturbation consisting in a constant acceleration motion to either approach or move away from the pad. Three acceleration values have been considered, according to the anticipated operational profile of the bearings. The results of the analysis yielded a map for each coefficient, at different values of rotational speed, thrust load and acceleration levels. 
Subsequently, a single degree of freedom model has been developed to predict the response of the bearing under a transient loading condition. The single degree of freedom model results have been validated by setting the displacement derived, as a predefined motion of the rotor in a new transient CFD analysis. The load function that resulted showed good agreement with the initial loading force applied to the single degree of freedom model.

Comparing the dynamic performance of the two bearing designs, namely the tapered-land and the textured pad thrust bearings, the following conclusions have been drawn:

(a) The tapered-land bearing is affected more significantly by fast load changes while the textured bearing displays a higher maximum film thickness difference when both bearings are set at the same initial minimum film thickness.

(b) If the same load is applied to both bearings, the textured pad bearing exhibits smaller minimum film thickness variation, because it operates at smaller values of minimum film thickness.

It is noted that operating minimum film thickness values of thrust bearings become smaller over time, for improved efficiency, therefore the dynamic behaviour analysis is getting more important to avoid unpredictable response and failures. Further, experimental procedures to evaluate transient behaviour are both expensive and time consuming, whereas direct transient simulations for a given thrust load are practically impossible, due to the constant remeshing requirement, for the calculation of the correct position (film thickness) at each time-step. Thus, the present work proposes an alternative feasible procedure to calculate the dynamic performance of thrust bearings, utilising a SDOF bearing model, with dynamic coefficients appropriately calculated with state-of-the-art CFD approaches.

\section{References}

1. Storteig E., White M., 1999, "Dynamic characteristics of hydrodynamically lubricated fixed-pad thrust-bearings”, Wear, Vol. 232, Issue 2, pp. 250-255, DOI: 10.1016/S00431648(99)00153-2.

2. Zhu Q., Zhang W. J., 2003, “A Preliminary Nonlinear Analysis of the Axial Transient Response of the Sector-Shaped Hydrodynamic Thrust Bearing-Rotor System”, ASME Journal of Tribology, Vol. 125, Issue 4, pp. 854-858, DOI: 10.1115/1.1575775.

3. Nica A., 1971, “A thermohydrodynamic method of bearing analysis”, Tribology., Vol. 4, Issue 4, pp. 218 - 226.

4. Jang G., Lee S., 2006, "Determination of the dynamic coefficients of the coupled journal and thrust bearings by the perturbation method", Tribology Letters, Vol. 22, Issue 3, pp. 239246, DOI: 10.1007/s11249-006-9087-7.

5. Srikanth D., Chaturvedi K., Reddy A., 2009, "Modelling of Large Tilting Pad Thrust Bearing Stiffness and Damping Coefficients", Tribology in Industry, Vol. 31, Issue 3\&4, pp. 23-27.

6. Papadopoulos C., Nikolakopoulos P., Kaiktsis L., 2012, “Characterisation of stiffness and damping in textured sector pad micro thrust bearings using computational fluid dynamics", ASME Journal of Engineering for Gas Turbines and Power, Vol. 134, Issue 11, pp. 854-858, DOI: $10.1115 / 1.4007320$. 
7. Qin K., Jahn I., Jacobs, 2016, "Prediction of Dynamic Characteristics of Foil Thrust Bearings using CFD”, 20th Australasian Fluid Mechanics Conference, Perth Australia, 5/128/12.

8. Snyder T., Braun M, 2018, “Comparison of Perturbed Reynolds' Equation and CFD Models for the Prediction of Dynamic Coefficients of Sliding Bearings”, MDPI Lubricants, Vol. 6, Issue 1, DOI:10.3390/lubricants6010005.

9. Takenaka K., Hayashi T., Miyagawa K., 2017, “Application of CFD analysis for static and dynamic characteristics of hydrodynamic journal bearing” Paper presented at the 17th International Symposium on Transport Phenomena and Dynamics of Rotating Machinery, ISROMAC 2017, Maui, United States, 16/12 - 21/12.

10. Li Q., Zhang S., Ma L., Xu W., Zheng S., 2017, "Stiffness and damping coefficients for journal bearing using the 3D transient flow calculation”, Journal of Mechanical Science and Technology, Vol. 31, Issue 5, pp. 2083-2091.

11. Vieira L., Cavalca K., 2012, "Analysis of the influence of force and moment dynamic coefficients on lubricated thrust bearings", 10th International Conference on Vibrations in Rotating Machinery, 11/09/2012 - 13/09/2012, pp. 557-566.

12. Fouflias D., Charitopoulos A., Papadopoulos C., Kaiktsis L., Fillon M., 2014, Charitopoulos, "Performance comparison between textured, pocket, and tapered-land sectorpad thrust bearings using computational fluid dynamics thermohydrodynamic analysis", Proceedings of the Institution of Mechanical Engineers, Part J: Journal of Engineering Tribology, Vol. 229, Issue 4, pp. 376-397, DOI: 10.1177/1350650114550346

13. Charitopoulos A., Visser R., Eling R., Papadopoulos C., 2018, "Design optimization of an automotive turbocharger thrust bearing using a CFD-based THD computational approach”, Lubricants 2018, Vol. 6, Issue 1, DOI: 10.3390/lubricants6010021.

14. Papadopoulos C., Nikolakopoulos P., Kaiktsis L., 2011, "Evolutionary Optimization of Micro-Thrust Bearings With Periodic Partial Trapezoidal Surface Texturing”. Journal of Engineering for Gas Turbines and Power, Vol. 133, Issue 1, pp., DOI: 10.1115/1.4001990

15. Chalkiopoulos M., Charitopoulos A., Fillon M.,Papadopoulos C., 2020, "Effects of thermal and mechanical deformations on textured thrust bearings optimally designed by a THD calculation method”, Tribology International, Vol. 148, Available online 15 March 2020. 